\title{
An Experimental Study of Nasa Shareera w.s.r to Pratimarsha nasya
}

\author{
Research Article
}

\section{Priya Rajan1*, Kanthi G M², Ravishankar B³}

1. Assistant Professor, Department of Shareera Rachana, Yenepoya Ayurveda Medical College, Mangalore. 2. Retd.Professor, Department of P.G. studies in Shareera Rachana, S.D.M college of Ayurveda, kuthpady, Udupi. 3. Director \& Professor of Experimental medicine, SDM Centre of research in Ayurveda and Allied sciences, Udupi.

\begin{abstract}
Nasa (nose) is considered as the Ghranendriya Adhishtana, whose functions are not only limited to olfaction and respiration but also considered as a pathway for drug administration. Acharya Vagbhata has explained in Nasya vidhi Adhyaya, as "Nasa Hi Shiraso Dwaram", while on Dinacharya Adhyaya he explained the nasal medications like Anutaila administration in nasal cavity. Nasya Karma (nasal drug delivery) is a therapeutic procedure where drugs are administered through nose in a specific manner, to cure different Jatrurdwa Vikaras. Pratimarsha Nasya may be practiced twice daily as dinacharya. It is described as the most convenient and well tolerated form of nasya as it does not lead to any discomfort or complications. It is suitable for all the age, from birth to death and serves both the purpose of Snehana and Sodhana. The Experimental Study was conducted on 18 healthy wistar stain albino rats of either sex grouped into 3 groups of six rats each to observe any histological changes after administering the drug and the results show that there is no histological changes in the nasal mucosa, olfactory bulb and olfactory area which shows that Anutaila Pratimarsha Nasya Karma through this route is safe and effective.
\end{abstract}

Key Words: Nasa, Dinacharya, Pratimarsha Nasya, Anutaila, Nasal cavity, Histology.

\section{Introduction}

Ayurveda emphasizes equal importance to preventive and curative aspects of diseases and mentions preventive aspects in detail such as Dinacharya, Ritucharya, Rasayana etc. Acharya Vagbhata has explained the nasal medications like Anutaila administration in nasal cavity as a part of Dinacharya(5). As a routine, daily we can use the Pratimarsha Nasya as a part of Dinacharya. Nasya Karma is a therapeutic procedure where drugs are administered through nose in a specific manner, to cure different systemic disorders(1-4).

The benefits of using Anutaila nasya as Dinacharya is mentioned clearly by Acharya Vagbhata(6).Two bindu in each nostril is the dose mentioned by Acharya Vagbhata(7)and Sharangadhara(8).Taila is ideal for nasya karma to be practiced daily because shiras is the chief sthana of kapha and even during swastha none is better than taila to produce the snehana effect(9). The nose is believed

* Corresponding Author:

Priya Rajan,

Assistant Professor,

Department of Shareera Rachana,

Yenepoya Ayurveda Medical College,

Naringana, Mangalore

Email id - priyarnambiar87@gmail.com to be the entrance of the cranial cavity. The medicine instilled through them easily penetrates and moves up to reach the shringataka, it spreads to the whole of murdha (brain), netra (eyes), srotra (ears), kantha (throat), and their siramukhas(10).

Previously work was carried out on Critical and comparative study of " nasa hi shiraso dwaram" (11) but experimental study was no done.

Purpose of this study is aimed to reveal the histological study of nasal cavity with brain (including olfactory bulb \& olfactory area) through animal experiment by administering Anutaila Nasya as specified in the Ancient Science.

\section{Materials and methods \\ Materials}

1. 18 Healthy wistar stain albino rats weighing about 150-200 gm were selected and divided into three groups (of 6 rats each) were obtained from the animal house attached to S.D.M centre for research in Ayurveda and Allied Sciences. The experiments were undertaken after obtaining permission from the institute's animal ethics committee and as per CPSEA guidelines. Clearance No: SDM-CAH-13-14-03.

2. Test drug: For this experimental study already prepared Anutaila from S.D.M. Pharmacy, Kuthpady, Udupi (reference from A.F.I) was taken. It was prepared according to the reference from Astanga Hrudaya Sutrasthana $20^{\text {th }}$ chapter. 
3. Cannula

4. Petri dish

$5.10 \%$ formalin

Photo No 1 Drug- Anutaila, Cannula

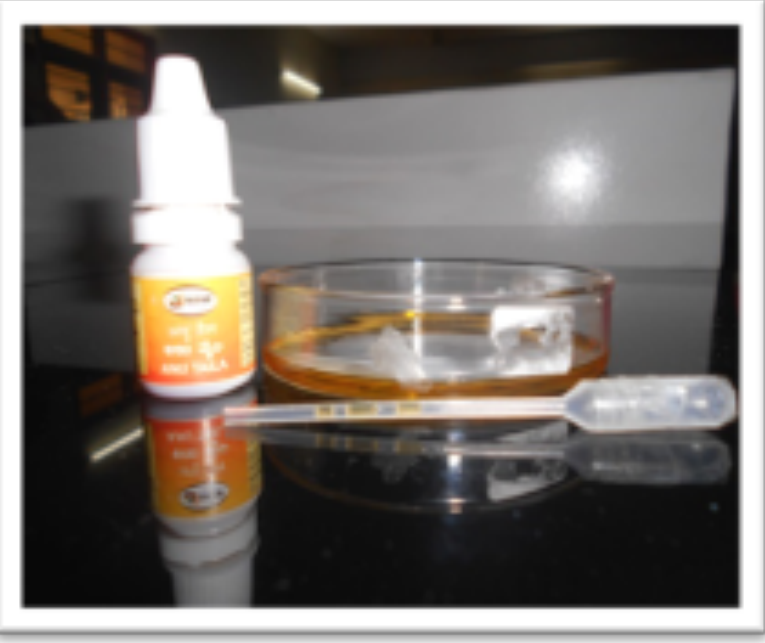

\section{Methods}

18 healthy wistar stain albino rats of either sex were selected randomly and divided into three groups of 6 rats each.

Group 1 was served as control group. The rats of this group were fed with normal food pellets and water ad libidum.
Rats of Group 2 were administered with two drops of Anutaila through nasal route for 15 days continuously daily morning at 10am.

Rats of Group 3 were administered with two drops of Anutaila through nasal route for 30 days continuously daily morning at 10am.

As it was Pratimarsha nasya poorva karma and paschat karma was not required. The nasya was administered with the help of a cannula. The rats were held by a helper in position and two drops of Anutaila was administered through Nasal route. Following the nasya course rats were provided with $100 \mathrm{~g}$ of food pellets and $100 \mathrm{ml}$ of warm water $\left(37^{\circ} \mathrm{C}\right)$. After $15 \& 30$ days of nasya administration, on 16th \& 31st day, rats were sacrificed with cervical dislocation.

Sacrificed rats were kept on dissection table. A median incision was made around the cervical region. The skin and underlying tissue from this area was removed, exposing the skull. Top of the skull was removed using a scissor tip to get just inside, then the entire bone was cut it into small pieces and removed. The brain was exposed. It was then isolated from the adjacent structures. The skin around cranial region was removed and then the nasal cavity was separated. Nasal cavity and brain (including olfactory mucosa, olfactory bulb and olfactory area) were dissected out carefully. Both the specimens were cleaned and were put into a solution of $10 \%$ formalin for fixation. The specimens were then sent for histological examination.

\section{Photo No 2 Drug administered through nasal cavity \\ Photo No 3 Cervical dislocation \\ Photo No 4 Dissection of brain \& nasal cavity \\ Photo No 5 Dissected
Nasal cavity \& brain}

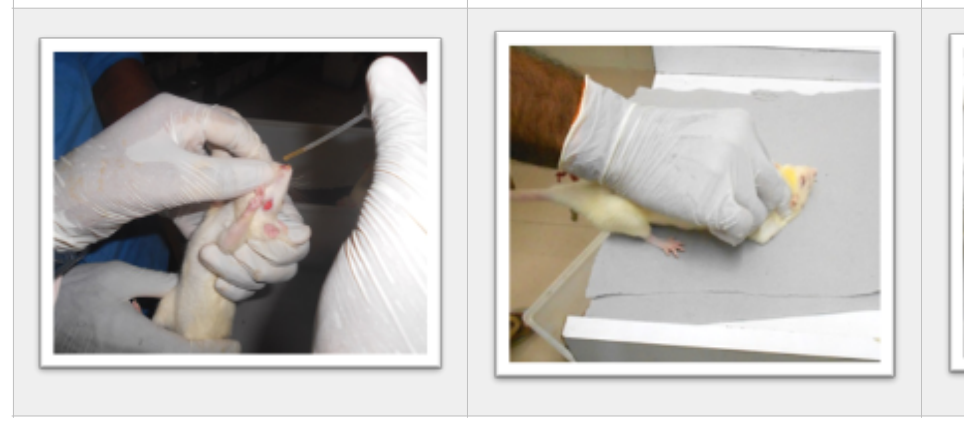

\section{Sudy, observations and results}

\section{Inclusion criteria}

1. Healthy rats of either sex were considered.

2. Wistar stain albino rats 90-120 days old, weighing about 150-200gms.

\section{Exclusion criteria}

1. Rats below and above the desired age and weight.

2. Pregnant and diseased rats.

3. Rats which are under trial for other experiment.
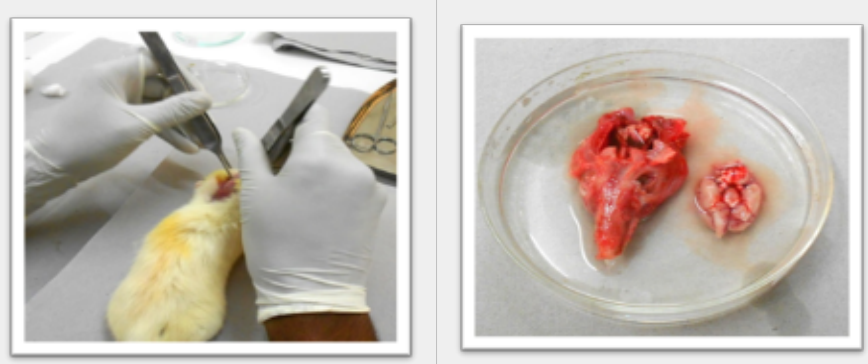

\section{Dose fixation}

Since the table of "Paget \& Barnes" (1969) for human dose to rat dose conversion is applicable only for oral administration, the rat dose for Anutaila Pratimarsha Nasya was fixed as two drops (in the cannula used for this experimental study). The dose was $0.04 \mathrm{ml}$ in each nostril.

\section{Route of administration} Route.
The drug was administered through the Nasal 


\section{Assessment criteria}

1. Normal histological study of group 1

2. Histological study of group $2 \&$ group 3

3. Observation \& Comparative study of group 1, $2 \& 3$

\section{Observations}

\section{General observations}

- Weight of the rats: The weight of rats of group 2 (after 15 days of Anutaila Pratimarsha Nasya) was observed. It is increased in 5 rats, except one rat, where there was a reduction of 2 grams. Whereas the weight of rats of group 3 (after 30 days of Anutaila Pratimarsha Nasya) was observed. It increased in all the six rats.

- Bowel and micturition habits: All the rats showed normal bowel and micturition. Changes in colour and consistency were not observed.

- Food and water intake: Rats of both test groups were fed with food pellets and water was given ad libitum. Changes in food and water intake were not observed.

- Irritation in the nose: In Group 2 rats, in $1^{\text {st }}$ week scratching of the nasal region with its paw were observed soon after administration of the Anutaila, which persisted for 3-4 minutes. By $2^{\text {nd }}$ week the time duration reduced to 1-2 minutes. In Group 3 rats, in 1 st week scratching of the nasal region with its paw were observed soon after administration of the Anutaila, which persisted for 3-4 minutes. By 2nd week the time duration reduced to 1-2 minutes and from $3^{\text {rd }}$ week onwards the scratching / nasal irritation stopped gradually.

- Running nose, redness, nasal discharges were not observed during the complete course of Anutaila Pratimarsha Nasya in rats of both test groups (group 2 \& group 3).

- All the rats taken for the experimental study were observed to be healthy throughout the course of study.

\section{Experimental study}

Histological observations were done under trinocular microscope are as follows:

\section{GROUP 1 (NASAL CAVITY)}

- The nasal cavity was divided into equal halves by the nasal septum.

- The cavities contain a dorsal meatus.

- At this level, the nasal cavity was lined by respiratory epithelium covering the septum, dorsal meatus, and turbinates.

- The fibrovascular lamina propria, in contrast to that in humans, was devoid of sebaceous glands and hair follicles.

- The Nasal mucous membrane was lined by squamous epithelium.

\section{GROUP 1 (BRAIN)}

- The histology of olfactory bulb of control group revealed three laminae. From without inward these laminae were; olfactory nerve layer, glomerular layer, and mitral cell layer, respectively.

- The fore brain sections from control group exhibited almost normal cytoarchitecture.

- Microscopic examination of the midbrain sections containing hippocampus and temporal lobe of control group rats revealed normal cellular organization.

\section{Observations}

Histological examination of nasal cavity in normal control group without administering Anutaila Pratimarsha Nasya revealed that the nature of arrangement of olfactory and respiratory mucosa, structure of the meatus, septum (cartilage), were having normal cytoarchitecture. Microscopic examination of the olfactory bulb and olfactory area revealed normal cellular organization.

\section{Microscopic observation of Nasal cavity, Nasal mucosa, olfactory bulb, Forebrain, Hippocampus \& Temporal lobe of Group - 1 (Normal Control Group)}

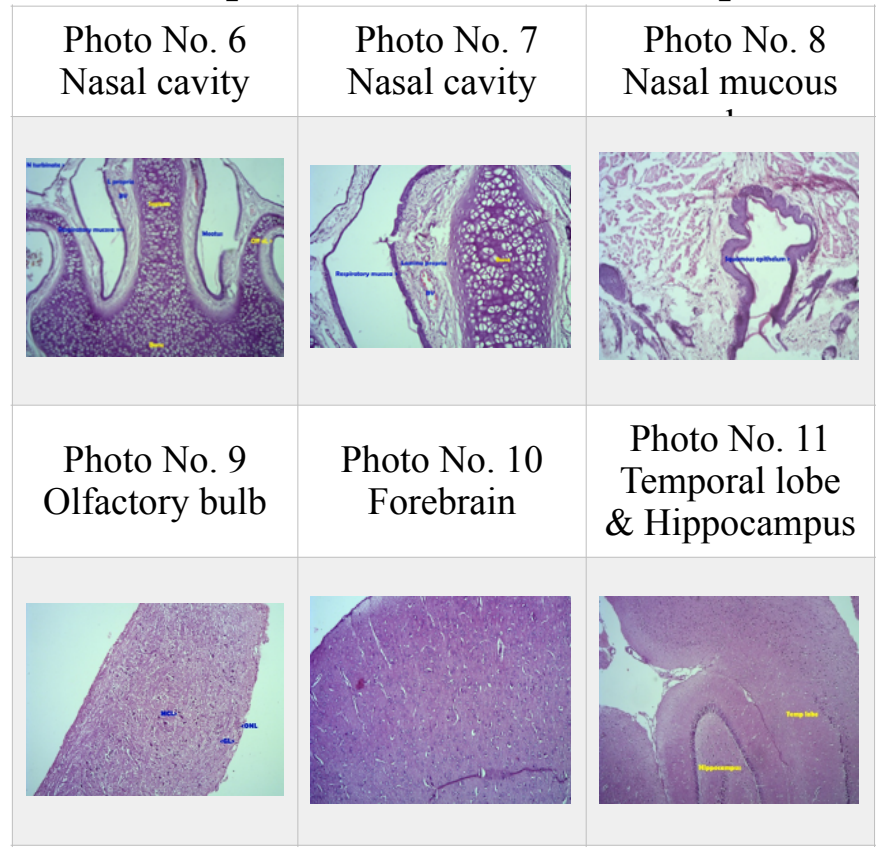

\section{GROUP 2 (NASAL CAVITY)}

- The nasal cavity was divided into equal halves by the nasal septum.

- The cavities containing a dorsal meatus and nasal turbinates were observed.

- At this level, the nasal cavity was lined by respiratory epithelium.

- The fibrovascular lamina propria was observed below the respiratory epithelium.

- Olfactory epithelium was observed on lateral aspect of the turbinate.

- Vomero-nasal glands were observed.

- Nasal cartilage was lined by connective tissue and blood vessels were observed. 


\section{GROUP 2 (BRAIN)}

- The histology of olfactory bulb of group-2 revealed five laminae. From without inward these laminae were; olfactory nerve layer, glomerular layer, external plexiform layer, mitral cell layer, and internal plexiform layer respectively.

- The fore brain sections from experimental group-2 exhibited almost normal cytoarchitecture.

- Microscopic examination of the midbrain sections containing hippocampus and temporal lobe of experimental group-2 rats revealed normal cellular organization.

\section{Observations}

Histological examination of nasal cavity in experimental group-2 after administering Anutaila Pratimarsha Nasya for 15 consecutive days revealed that the arrangement of olfactory and respiratory mucosa, structure of the meatus, septum (cartilage), vomero-nasal organ were having normal cytoarchitecture compared to the normal control group-1. Microscopic examination of the olfactory bulb and olfactory area revealed normal cellular organization. The drug administration did not affect the cytoarchitecture of the nasal mucosa, olfactory bulb and olfactory area.

\section{Microscopic observation of Nasal cavity, Nasal mucosa, olfactory bulb, Forebrain, Hippocampus \& Temporal lobe of Group - 2 (15 days of Anutaila Pratimarsha Nasya)}

\begin{tabular}{|c|c|}
\hline No. 12 & Photo No. 13 \\
\hline Nasal cavity & $\begin{array}{l}\text { Nasal mucous } \\
\text { membrane }\end{array}$ \\
\hline
\end{tabular}

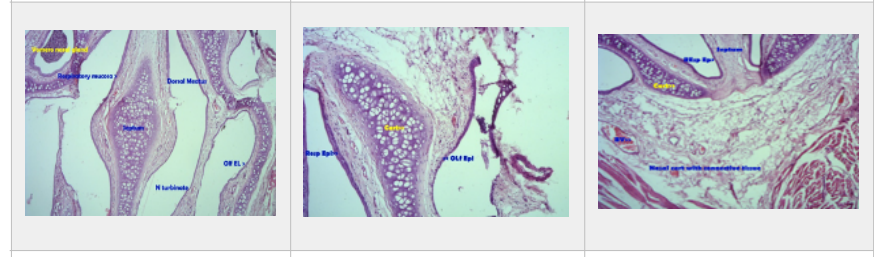

Photo No. 15 Olfactory bulb Photo No. 16 Forebrain
Photo No. 17

Temporal lobe \& Hippocampus

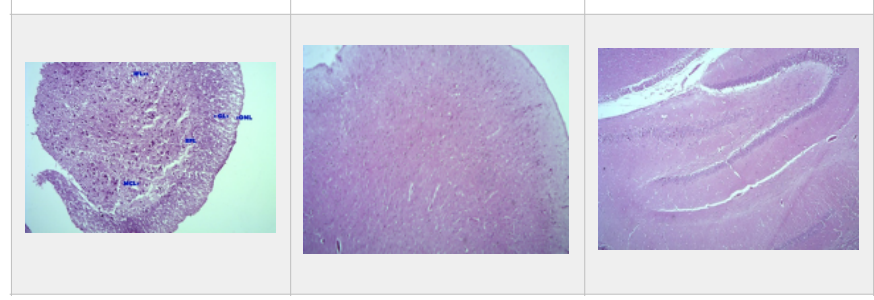

GROUP 3 (NASAL CAVITY)

- The nasal cavity was divided into equal halves by the nasal septum.

- The cavities contain a dorsal meatus and nasal turbinates were observed.

- At this level, the nasal cavity was lined by respiratory epithelium.

- The fibrovascular lamina propria was observed.

- Olfactory epithelium was observed on lateral aspect of nasal turbinate.

- Nasal cartilage was lined by connective tissue were observed.

\section{GROUP 3 (BRAIN)}

- The histology of olfactory bulb of group-3 revealed five laminae. From without inward these laminae were; olfactory nerve layer, glomerular layer, external plexiform layer, mitral cell layer, and internal plexiform layer respectively.

- The fore brain sections from experimental group-3 exhibited almost normal cytoarchitecture.

- Microscopic examination of the midbrain sections containing hippocampus and temporal lobe of experimental group-3 rats revealed normal cellular organization

\section{Observations}

Histological examination of nasal cavity in experimental group-3 after administering Anutaila Pratimarsha Nasya for 30 consecutive days revealed that the nature of the arrangement of olfactory and respiratory mucosa, structure of the meatus, septum (cartilage), vomero-nasal organ were having normal cytoarchitecture compared to the normal control group-1.Microscopic examination of the olfactory bulb and olfactory area revealed normal cellular organization.The drug did not affect the cytoarchitecture of the nasal mucosa, olfactory bulb and olfactory area.

\section{Microscopic observation of Nasal cavity, Nasal mucosa, olfactory bulb, Forebrain, Hippocampus \& Temporal lobe of Group - 2 (30 days of Anutaila Pratimarsha Nasya)}
Photo No. 12
Photo No. 13
Photo No. 14
Nasal cavity
Nasal cavity
Nasal mucous

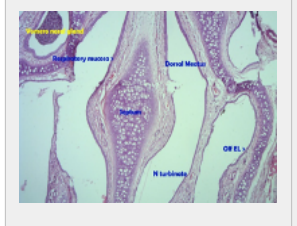

Photo No. 15 Olfactory bulb

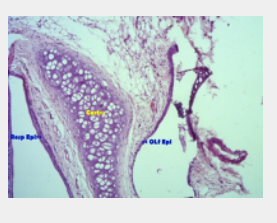

Photo No. 16 Forebrain

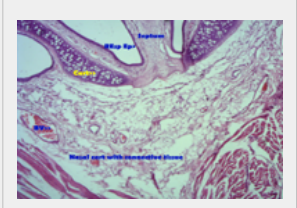

Photo No. 17 Temporal lobe \& Hippocampus
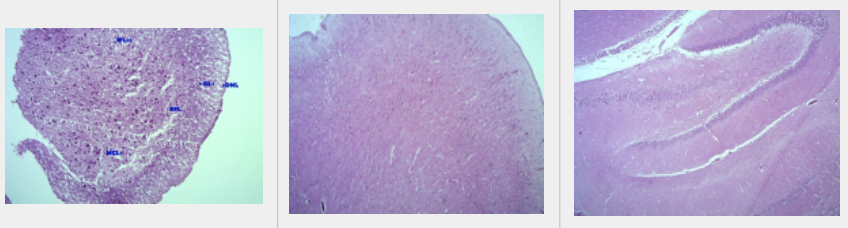


\section{Discussion}

\section{Discussion on experimental study}

In Ayurvedic classics use of animals for testing the effect of drug and toxicity of the Ahara is mentioned. Experimental studies are convenient due to many advantages like uniformity, ideal controls, less risky and sufficiency of data in shorter time, which helps us in arriving at a rational inference and refine the art of therapeutics. The anatomical and physiological resemblances of certain animals with that of humans help in conducting the studies and thereby the action of various therapeutic formulations can be evaluated. Drugs have been administered nasally for therapeutic and recreational purposes since ancient times. The interest in and importance of the systemic effects of drugs administered via the nasal route have expanded over recent decades.

Nasal delivery is a feasible alternative to oral or parenteral administration for some drugs because of the high permeability of the nasal epithelium, rapid drug absorption across this membrane and avoidance of hepatic first-pass metabolism. Ethical issues as well as difficulty in obtaining enough human nasal tissue specimens have called for the need to use alternative experimental methods. This justifies the use of "Nasya karma" to assess its effect in experimental models and thus to "evaluate the efficacy of Pratimarsha Nasya in healthy rats."

The experimental study was undertaken by administering Anutaila Pratimarsha Nasya through nasal route for different time durations, for analyzing the histological changes in the nasal cavity and brain. The experiment was carried out on healthy rats without administering Nasya and after administering Nasya for 15 and 30 days for better understanding of Nasal cavity and brain.

All the Acharyas have explained the practice of Nasya Karma as Dinacharya. Acharya Vagbhata explained the nasal medications like Anutaila administration in nasal cavity as Dinacharya, which means that there are no restrictions to administer Anutaila Pratimarsha Nasya daily. According to Acharya Charaka, for Pratimarsha Nasya the finger is dipped into medicated oil and then instilled into the nostrils, and adds that it is not necessary to be snuffed deeply as done in other types of Nasya whereas Acharya Susrutha states that the Sneha put into the nostrils which comes out when the person sucks the air upward from the nose should be understood as the ideal quantity of Pratimarsha Nasya. Vruddha Vagbhata mentions the dose as either two bindu or even one bindu, whereas Laghu Vagbhata mentions as two bindu. It is Acharya Sharangadhara who clearly specifies the dose as two bindu in each nostril. Since the table of "Paget \& Barnes" (1969) for human dose to rat dose conversion is applicable only for oral administration, the rat dose for Anutaila pratimarsha Nasya was fixed as two drops (in the cannula used for this experimental study). The dose was $0.04 \mathrm{ml}$ in each nostril. So this study was carried out with different duration of Pratimarsha Nasya as 15 days and 30 days, in an increasing order.

\section{Discussion on histological study}

The main objective of carrying out this study was to determine whether Anutaila Pratimarsha Nasya Karma induces any histological changes in the nasal mucosa and the olfactory pathway. For this purpose the effect of the above procedure was assessed by histological examination.

During the histological examination of the nasal cavity sections from different groups, the focus was on the nature of the arrangement of olfactory and respiratory mucosa, structure of the meatus, septum (cartilage), and vomero-nasal canal. Sections from control group were generally found to be normal hence considered as referral sections for evaluating sections from test groups. The septum cartilage, respiratory mucosa, olfactory mucosa, the underlying connective tissue or lamina propria with blood vessels and vomeronasal canal were having almost normal cytoarchitecture in both the test groups which was comparative with the normal control group, which indicates the safety of the nasal mucosa by administering Nasya Karma through the nasal route.

Microscopic examination of the hippocampal \& temporal lobe sections from control group was carried out and the profile was used to compare the microscopic profile of sections from test groups. No remarkable difference between control group sections and sections from test groups could be identified. Microscopic examination of fore brain sections from both normal control and test groups was carried out at different magnifications. Control group sections exhibited normal profile with distinct outer granular layers, blood vessels and pyramidal layers. The sections from test groups also exhibited almost similar profile. Microscopic examination of the olfactory bulb from control group was carried out and the profile was compared with the microscopic profile of sections from test groups. No remarkable difference between control group sections and sections from test group could be identified and showed normal cytoarchitecture.

Histological examination of brain region revealed that Anutaila Pratimarsha Nasya did not affect the cytoarchitecture of the olfactory bulb and olfactory area (located on the base of the frontal lobe and medial aspect of the temporal lobe) of the test groups which was comparative with the normal control group.

Based on the data generated and careful analysis it can be inferred that that there is no toxic or harmful effect by administration of Anutaila Pratimarsha Nasya daily as Dinacharya. 


\section{Conclusion}

The highly developed Modern medical science have carried out many researches on nasal drug administration like Intranasal administration of drugs in rats for evaluation of the transport of drugs to the systemic circulation and central nervous system and the pharmacological effect etc and proved that nasal route is an attractive alternative to invasive administrations, and provides a direct access to the systemic circulation. After analyzing the histological changes in the nasal cavity and brain it is found that cytoarchitecture of the nasal mucosa, olfactory area and olfactory bulb of both group 2 and group 3 is same as group 1(control group). Hence we can conclude that there is no significant change of histology by administering the Nasya Dravya. So, the Nasal route is safe.

However, detailed study with more number of parameters and study duration would provide data for arriving at un-equivocal inference.

\section{References}

1. Pandit Hari Sadashiv Shastri Paradkar. Ashtanga Hridaya of Vagbhata with Sarvanga Sundara Vyakhyana of Arunadatta and Ayurveda Rasayana of Hemadri. Reprint 2010, Varanasi; Chaukhambha Sanskrit Sansthana; 2010, 287p.

2. Vaidya Jadavji Trikamji Acharya. Charaka Samhitha of Agnivesha. Reprint 2010, Varanasi; Chaukhambha Sanskrit Sansthana; 2007, 723p.
3. Vaidya Jadavji Trikamji Acharya. Charaka Samhitha of Agnivesha. Reprint 2007, Varanasi; Chaukhambha Sanskrit Sansthana; 2007, 723p.

4. Shivprasad Sharma. Astanga Samgraha of Vruddha Vagbhata with sashilekha commentary. Varanasi; Chaukhambha Sanskrit Sansthana; 2008, 224p

5. Shivprasad sharma. Astanga Samgraha of Vruddha Vagbhata with sashilekha commentary. Varanasi; Chaukhambha Sanskrit Sansthana; 2008, 18p.

6. Shivprasad sharma. Astanga Samgraha of Vruddha Vagbhata with sashilekha commentary. Varanasi; Chaukhambha Sanskrit Sansthana; 2008, 18p.

7. Pandit Hari Sadashiv Shastri Paradkar. Ashtanga Hridaya of Vagbhata with Sarvanga Sundara Vyakhyana of Arunadatta and Ayurveda Rasayana of Hemadri. Reprint 2010, Varanasi; Chaukhambha Sanskrit Sansthana; 2010, 292p.

8. Pandit Parashurama Shastri. Sharangadhara Samhitha of Sharangadhara with Adhamallas's Dipika \& Kasirama's Gudhartha dipika commentary. Varanasi; Chaukhambha Sanskrit Sansthana; 2006, 344p.

9. Pandit Hari Sadashiv Shastri Paradkar. Ashtanga Hridaya of Vagbhata with Sarvanga Sundara Vyakhyana of Arunadatta and Ayurveda Rasayana of Hemadri. Reprint 2010, Varanasi; Chaukhambha Sanskrit Sansthana; 2010, 293p.

10. Shivprasad sharma. Astanga Samgraha of Vruddha Vagbhata with sashilekha commentary. Varanasi; Chaukhambha Sanskrit Sansthana; 2008, 300p.

11. Vaidya M.S. Baghel. Researches in Ayurveda, Mridu Ayurvedic Publication, 2005, 194p. 